\title{
Individuality or conformity? Identity in personal and university academic homepages
}

\author{
Ken Hyland
}

University of Hong Kong

\begin{abstract}
The connection between writing and identity has been a subject of academic interest for some time and there is now broad agreement that identity is created from the texts we engage in and the semiotic choices we make. In this view, the process of constructing an identity most clearly involves selecting materials to present to others, a process which is seen most directly in personal homepages. It has become almost obligatory for academics to maintain some kind of online presence, although these homepages can also serve the university in several ways and therefore suppresses more personal facets of identity and act to position the author as an employee. As a result, many academics seek to escape the bland uniformity of the university personal page to present a more multi-faceted identity in a selfmanaged homepage. This paper explores the this relatively neglected area of composition to show how identity is discursively constructed in a corpus of 100 homepages of 50 academics, one universitymanaged and the other personally created. Focusing on textual content, design, links and photographs, I contrast some of the ways that academics elect to represent themselves as academics in these two environments.
\end{abstract}

\section{Keywords}

Homepages; identity; academic discourse; multimodal texts 


\section{Individuality or conformity? Identity in personal and university academic homepages}

\section{Introduction}

The personal homepage is now a ubiquitous feature of everyday life as increasing numbers of people of all ages and walks of life seek to present something of themselves to a potentially massive audience. This is a genre which offers insights into how individual's manage their sense of self online, but at the same time it reveals the tensions involved in projecting a public identity .

Academics have not been slow to embrace this medium. A few years ago, for example, a study of the social networking practices of over half a million academics found that $71 \%$ had at least one homepage (Tang et al, 2007). It has, in fact, become almost obligatory for academics to maintain some kind of online presence to satisfy inquiries from various groups, with researchers, students, conference organizers, editors, publishers, university administrators, and recruitment head-hunters among those seeking information about individual scholars. But more than merely a glorified Yellow Pages, the personal homepage is a valuable tool for supporting a particular version of the author, representing how he or she wishes to be seen by others. It can, however, also serve institutional ends: offering online resources for students, displaying the credentials of scholars at the university, and functioning to advertise and promote departments, courses, and fundraising activities.

In fact, the absorption of universities into a promotional culture (e.g. Fairclough, 1995) means that 'as a faculty member designs her homepage, it becomes an advertisement for the faculty member, yet it is also an advertisement for the department and university' (Hess, 2002: 172). This institutional governance of university homepages is perhaps what leads many academics to construct alternative online spaces of self-representation, where they might offer a richer and more varied version of themselves. Focusing on the discoursal construction of identity of 50 academics in their universitymanaged and personally created homepages, I explore this tension between the personal and the professional and what this tells us about identity in academic contexts. First, though, I need to sketch the character of this genre, its relationship to identity and its importance in academic life. 


\section{Homepages and identities}

One reason for the popularity of the personal homepage is the fact that no other medium is better suited to fulfilling the present-day demands of identity work, balancing the apparent fragmentation of modern life with the construction of coherence and meaning. The postmodern view of identity, understood as a patchwork (Kraus, 2000) or pastiche (Gergen, 1991) of independent and partially contradictory sub-identities, finds its expression in a medium which is always "under construction" and which can be regularly updated to reflect the latest self-conceptions. It is also a genre which facilitates the joining of diverse and diachronic self-aspects and sub-identities with links in its hypertext-structure (Chandler, 1998). Representing one's patchwork identity on a personal home page can therefore help foster the feeling of self-integration and self-effectiveness, but more than this, and at the same time, it is especially well suited for an elaborate strategic self-presentation (Chandler, 1998; Wynn \& Katz, 1997).

This kind of self representation is important as identity involves identification: it means identifying oneself as belonging to a particular group of valued others by appropriating its discourses and taking on the understandings, allegiances and values which membership that social group, including disciplines, involves. In this way we can see identity not as a state of being a particular person but the process of assembling and changing that person over time through interactions with others. The tensions involved in this process, of conforming to the expectations of the group and making space for ourselves, between achieving credibility as insiders and reputations as individuals, is thrown into sharp relief in the homepage.

One reason for this is that we can see the act of composing a homepage as a process Levi-Strauss (1974) described as bricolage, where the author doesn't so much write, but assembles a depiction of the self through a rational, conscious and deliberate inclusion, exclusion, adaption and arrangement of material. This assembly of symbolic resources brings together various cultural attributes that are likely to be valued by a particular target community of readers. It therefore reflects something of the author's assumptions about community norms and values from which identity is constructed for 
public approval. More than this, however, it also facilitates self-dialogue (Chandler \& RobertsYoung, 1998) as the process of assembling these elements is itself an important way of discovering, or at least clarifying one's thoughts, feelings and identity. It therefore reflects Giddens' (1991) view that self and reflexivity are interwoven, so that identity does not involve the possession of particular character traits, but the ability to construct a reflexive narrative of the self.

The homepage, then, might be seen as an autobiographical reconstruction which allows subjects to reconceptualise their actions and attributes to represent a coherently motivated picture of continuity and sameness to others. It combines the psychological need for cognitive integration with the sociological need for self-representation and group membership. Drawing on various modalities, with an attractive, information-rich presentation, they can strategically manage the impression they make on people who have never met them. Thus for Parks \& Archley -Landas (2003) the homepage provides 'an incredibly flexible and unencumbered stage for the construction of identity', but one we should see as always negotiated in a social context. Identity is a socially constructed, emergent process which draws on structured, symbolic discourses to suggest individual expertise and group membership. So through their choice of design, language, links, images and content, authors recognize the conventions and behaviours of particular social groups and display their membership of these groups. Such selections make a claim for a particular identity, signalling implicit norms and beliefs to reveal a self immersed in a given milieu but also as a distinctive constituent of it.

\section{Tensions in the academic homepage}

The personal homepage is a medium for the kind of public relations work which can help create a credible and valued persona. It is the identity claim par excellence and for academics provides a platform for global visibility and a declaration of academic standing. But while the appeal of composing a homepage may be to control one's representation of self online, the academic homepage actually seems to remove many of these choices. Instead, homepages 'reflect institutional rituals and are clearly generated to satisfy the objectives of employers' (Chandler, 1998: 8). This publicity blurb from a webpage design company trumpets some of the advantages of this: 
Does your faculty or lab Web page accurately reflect your professional identity? College web sites have become a major source of academic information, so it is essential to have a strong web presence. Whether you run a research lab, an academic program, a department, or an entire college, your web site is the best way to explain what you're doing and why it is so exciting! (http://www.academicwebpages.com/) The academic homepage thus shows us a particular individual, but an individual supported by an institutional server and linked into a network of scholastic colleagues, publications, interests, courses and students. The coercive governing of institutional identity construction thus asserts the professional credibility of the individual by marginalizing other aspects of the self.

Academics obviously recognise the value of a prominent academic identity to their careers and reputations, after all, their careers, success and even their jobs may depend on it. Their academic selves are not ALL they are, however, and they risk having their online identities high-jacked by the institution and shaped by a template to project a positive view of the university. From a Foucauldian perspective, the individual is disempowered and discursively constructed as an employee by institution design teams. This regulation means that the university 'owns' the homepage and so also the identity that it constructs for the individual academic, appropriating his or her expertise for its own purposes. As Thoms and Thelwell (2005) observe:

The institution merely constructs these (academics) in the model that is ideologically suited in order to promote the institution. Academics are thus denied any autonomous subjectivity construction, and yield to the constructed display items in the university electronic window.

Dumont and Frindte (2005), for example, found that information about research activities dominated the contents of psychologists' homepages, while Hess (2002) and Arnold \& Miller (2001) observe that the directory-like character of university homepages marginalise the individual.

The depiction of a purely one-dimensional academic identity means that important aspects of the self, which help shape one's sense of uniqueness and can influence the kind of academic identity the individual performs, are lost to university governance (e.g. Hawisher \& Sullivan, 1999). Pages generated to satisfy the objectives of employers, or even generated by employers from templates, 
often fail to reflect the ways the authors would have chosen to represent themselves (Chandler, 1998) and suggests the willingness of subjects to surrender both their autonomy and their control over their representations of self. It legitimates the power of the university as the individual becomes 'just another academic': a cog in the corporate wheel whose identity simply reflects an institution's marketing ideology.

Consequently, many academics seek to regain some control over their public presentation of identity by creating their own pages independently of the slick uniformity of university branding. That authors feel a need to do this presumably suggests some desire to present a more nuanced and rounded version of themselves online: to reclaim facets of their identity lost to an institutional representation. The fact that pages are generally housed on a university server and indexed and searchable from the main university site, however, often results in a similar product. In the following sections I explore both 'official' university managed websites and personally designed pages to show both the ways identity is constructed in this medium and to better understand what this tells us about these different social contexts.

\section{Data and method}

The data for the study comprises 100 homepages: 50 university hosted pages and 50 individually managed pages paired with the same authors. Subjects were chosen equally from philosophy and physics, representing contrasting fields from the humanities and hard sciences respectively, and selected from the top 30 of the QS-Times Higher world University rankings for 2010 (2011). The QS-THS listings rank over 600 universities based on six indicators: the proportion of international students and staff, citations per faculty, staff-student ratio and employer views, but weighted heavily (40\%) towards an opinion survey of 10,000 academics world- wide. This list therefore provided an international base of comparable institutions with authors affiliated to institutions in 10 countries.

In addition to these selection criteria, authors were included only if they maintained a personal page in addition to that hosted by their institution. As far as possible, the corpus was also stratified 
according to rank and gender, with roughly equal numbers of full professors and Assistant Professors and of men and women from each discipline. The decision to select authors by their discipline, academic status and gender was guided by the possibility that these social factors might influence the ways writers presented themselves in this genre. I then used NVivo 8, a qualitative software programme, to code the text in both homepage corpora, identifying what authors chose to mention. The position, size and content of photographs were also recorded and the hypertext links were followed and categorized.

\section{Identity on the university homepage}

The following sections focus on the semiotic representation of subjects in the university-managed homepages, examining the ways that visual, textual and hyperlink features construct identity.

\subsection{Visual design}

Homepages are distinctive media formats in which form is as important as content so that authors are represented not only by what is said but visually through images, page layout, and colour. The most striking feature of the university staff pages is their glossy uniformity which has come to mimic the commercial pages of international corporations. Dramatic falls in central government funding in recent years has meant greater competition between institutions for student fees as a source of income and encouraged the emergence of an ideology of 'students as customers'. This corporatization of Higher Education has seen webpages become increasingly important as instruments of advertising where formatting and colour are determined by the institution and duplicated for every member in a department to impose a branding on those who work for it.

In this context the names, titles and photographs of academics appear secondary to the insignias of the university and department. University logos tend to dominate academic homepages with banner text along the top, departmental links down the side and webmaster information along the bottom. These features act as symbols of ownership which help position the individual as an employee, serving the corporate interests of the employing institution and squeezing the space available to the individual academic. The two homepages reproduced as Figs 1 and 2 are typical of this. 
Figure 1: Harvard academic university homepage

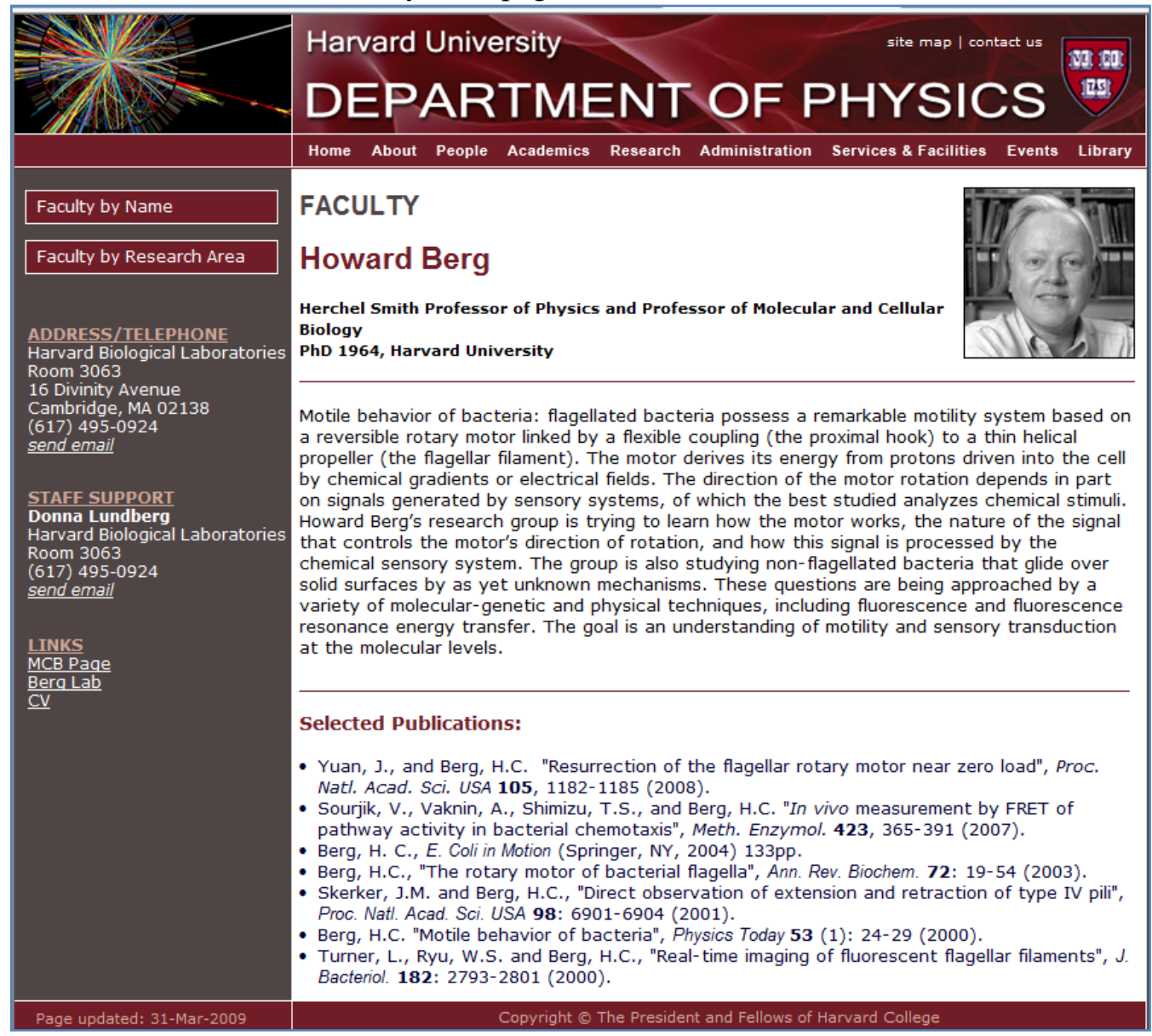

Figure 2: University College London academic university homepage

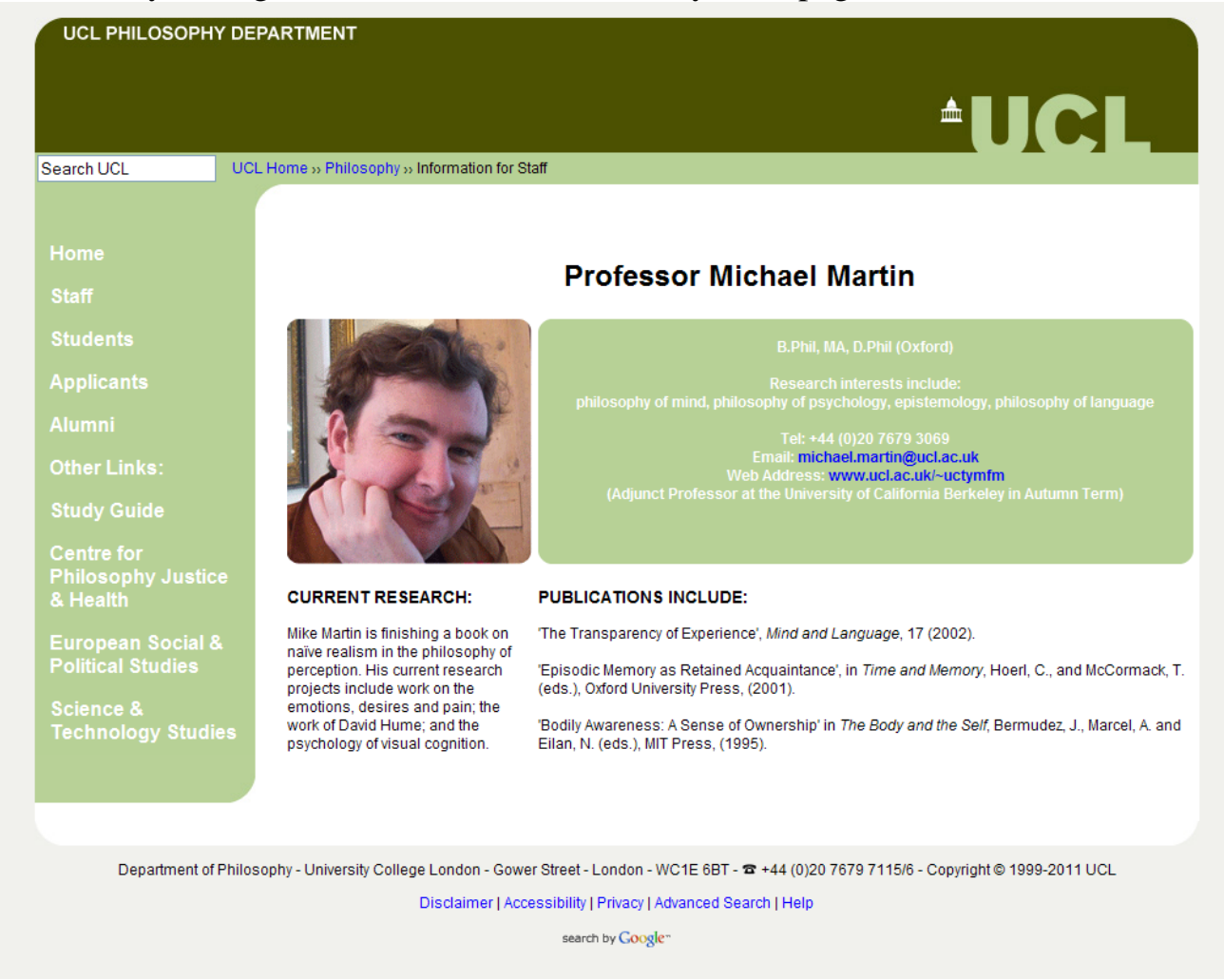


What is interesting about these homepages, yet also very typical in the corpus, is the way that academics are positioned in the context of their universities, so while located in different disciplines, universities, and countries, these homepages appear remarkably similar. They share a compositional unity derived from a horizontal and vertical-grid structure, and this unity is reinforced by the choice of narrow colour range to impart credibility to their subjects through what Kress and van Leeuwan (1996) call 'high modality'. The pages are dominated by banner headings proclaiming the subjects' respective departments and universities and carrying institutional logos, and by sidebars with departmental information so that the area available to the academic is restricted to about half of the screen. In this remaining space, the subjects present themselves through a brief paragraph, contact details, publication list, and a photograph. The repetition of these features across an entire department serves to construct the subject as just one academic among many and subjugates his or her individuality to the marketing principles of the institution.

The placement of visual and textual elements is also significant, so that the department banner at the top of the page signifies superiority and is given clear prominence. Similarly, following left to right reading conventions, we assume the text on the left, providing information on departmental and institutional topics, is intended to be scanned first. Following Kress and van Leeuwen's (1996) analogy with written texts, however, it is what occurs on the right which is regarded by the viewer as key information. This is where we find the 'message' while the left is what may be assumed to be known already. In other words, the institutional paraphernalia of information for students, links to the university and seminar programmes are presented as a context in which we 'read' the author himself. It is the agreed upon point of departure for the representation of the academic's individual identity.

The subject's photograph is a salient presence in the mainly textual space available to the academic. All but two university homepages in the corpus contained a photo of the author, positioned alongside the written text and always of the subject alone. While photographs allow viewers another way of understanding the subject, over $80 \%$ of these were a tightly cropped portrait with no articulated background. Where a background could be discerned it was likely to be an office. This absence of 
setting not only eliminates personal information about the subject, but disconnects him or her from time and place, reducing the individual to a generic academic filing a vacant place on the homepage. As Hess (2002: 179) observes, such standardized portraits "limit depictions of the individual's role within the academy to those of traditional academic workers defined by credentials".

In this space, the subject's photograph is asked to perform a great deal of semiotic work, competing with the colours, text and professional design of the homepage to offer the visitor more of a human representation of the academic subject. Here is a face behind this provider of texts and courses and a real person within what can appear an overwhelming corporate presence. While the photographs in the university pages often resemble the austere format of the passport image, the fact that subjects generally showed themselves smiling might be seen as an important means of 'identity management' (Jaffe et al, 1995). The smile invites a connection of social affinity and it is the subject's gaze which dominates, in the two pages here as in most of these portraits. The author looks directly at the viewer, bringing about a somewhat closer relationship between the webpage authors and those interested in discovering more about them. A contact is established which augments the rather stark textual information and fleshes out something of the purely professional persona that is depicted there.

\subsection{Textual choices}

While visual representation is important, what writers chose to say about themselves is perhaps the most significant way of constructing an online identity and, unsurprisingly, the university homepages highlighted the professional aspects of subjects, constructing them as credible academics. Subjects were positioned in terms of their employment, research interests and publications with current work (91\% of all homepages) and recent publications (83\%) dominating this content.

It is little surprise to find publications and research forming a key aspect of academic identity claims. Publication is 'the life blood of academia' (Becher \& Trowler, 2001) and a key index of academic standing as both the promotion of knowledge and the establishment of reputation depend on it. Books and articles are the currency of academic credibility and a badge of disciplinary membership. 
Writers in both fields therefore posted their publication outputs, although with differences. While physicists often simply listed a few recent references or a hyperlink (in 29\% of pages), philosophers generally provided a commentary on the book and its argument or impact (54\%):

(1) She is the author of four books. The Sources of Normativity (Cambridge 1996), an expanded version of her 1992 Tanner Lectures, examines the history of ideas about the foundations of obligation in modern moral philosophy and presents an account of her own. Creating the Kingdom of Ends (Cambridge 1996) is a collection of her essays on Kant's Ethics and Kantian Ethics. The Constitution of Agency (Oxford, 2008), is a collection of her recent papers on practical reason and moral psychology. And SelfConstitution: Agency, Identity, and Integrity, (2009) is a book about the foundation of morality in the nature of agency. She is also one of the editors of Reclaiming the History of Ethics: Essays for John Rawls (Cambridge 1997).

Publication lists and descriptions not only represent the expertise of the individual, legitimating his or her professional standing, but also illustrate the extent of the research activity in which the university is engaged. For the institution it underlines its authority and participation in producing the most valued of commodities: knowledge.

Writers in both disciplines also had a lot to say about their research interests. While philosophers usually $(71 \%)$ expressed this in the first person (2), Physicists tended to employ the third person (65\%) and to establish an identity through their lab membership (3):

(2) My research focuses on thoughts and utterances that don't fit standard propositional models. I am especially interested in cognitive "perspectives", in which one thought structures our overall understanding of a topic in a way that's similar to the way a concept like duck or rabbit can structure our perceptual experience.

I am mainly interested in how scientific method could possibly lead us to true generalizations about Nature; generalizations that extend infinitely beyond our current, finite perspective.

(3) How did the Universe begin? Chao-Lin Kuo's group seeks to answer this profound question by studying the most ancient light, the Cosmic Microwave Background radiation, emitted when the universe was in its infancy. 
Jenny Hoffman is interested in how electrons behave in novel materials. Research in the Hoffman laboratory at Harvard revolves around scanning probe microscopies of exotic correlated electron materials. Hoffman's team has designed and constructed three low-temperature microscopes to measure nanoscale electronic and magnetic properties.

Interestingly, these descriptions were often written for a non-specialist audience, claiming an interest and importance for their work to a wider scientific community.

A description of the writer's interest therefore functions to both advance the expertise and disciplinary competence of the homepage owner as well as promote the specialism and the research group to graduate students and other academics. We can also distinguish different orientations to community and epistemology in this rhetorical representation of insider competence. The philosophers tend to characterize themselves in terms of the more individualistic ethos of a discipline which sees interpretations and arguments as the creative insights of the author, while the physicists position themselves as players in a domain where results are the collective endeavours of a team. Here knowledge is shared and part of a cooperative context rather than personally owned (Hyland, 2012).

\subsection{Hypertext Links}

The examples in Figs 1 and 2 also show the significance of hypertext links in constructing the subject as a worker. This is because links do not merely offer readers different pathways through the text but also make available a means of identity construction by way of the 'virtual community' that the author creates (Miller, 1995; Rheingold, 1995).

Generally, links enable authors to engage with readers by setting up relations to other texts, indicating social allegiances in a process which Danath and boyd (2004:2) refer to as "public displays of connection". Hyperlinks potentially symbolize significant associations for the individual, thus helping to construct and legitimize identity is by these associations (e.g. Turkle, 1996). Who we publicly wish to be associated speaks of how we want to be seen, the communities we belong to, the interests we have and the people we value. But not all links are the same. While individuals may use 
them as verbal invitations, encouraging the viewer to discover more about the person they have sought out, institutional links are more like a directory of further information about the institution.

What is striking in the university-managed pages, in fact, is the dominance of institutional links. On Berg's page in Figure 1, for example, there are eight links to department matters, five to the university, five to research groups and two to web management. Just one link is provided by the researcher himself, taking the viewer to his cv. Martin's page similarly has 21 links, with ten to the department and six to site management, and just two personal links: one an email address and the other to a personal page. This imbalance acts to enmesh the author in an institutional web where he or she is appears as another resource of the university alongside courses, research groups and upcoming events. The interconnected spectrum of university practices, programmes and people thus help to situate the academic's identity as an institutional functionary. Links actually undermine the potential interactivity available to authors to represent him or her as a cog in a corporate machine. Overall, almost two thirds of the 700 links in the university staff pages connected to institutional targets and just $11 \%$ to aspects of the individual subject. It may be no surprise then, that academics seek to reclaim some control over the ways they are depicted in university pages.

\section{Identity on personal pages}

Personally-constructed pages are strikingly different from those on university websites, suggesting a conscious effort by authors to both extend their self representation to other facets of their experience and to recontextualise their academic selves in a less overwhelmingly commercial environment. Rejecting the polished corporate gloss, these pages are altogether more idiosyncratic and distinctive, reflecting in their design the decisions, and expertise, of their creators, and in their text a different take on their persona. As with the institutional pages, I will look at design, text and links in turn.

\subsection{Visual design}

While the attractiveness of a website design both appeals to readers' artistic sense and what they remember about it later (Bonnardel, Piolat \& Le Bigot, 2010), these 'home-made' pages seemed to 
employ a different aesthetic. Some were just a simple html file created using a word processing editor like Netscape with a few links on a bare white background. Others showed more flair and sophistication and were produced using web-design software such as Netvibes or WordPress and presented with images and obvious planning. Some were divided into separate windows, some had counters to record hits, one or two included blogs and feeds from other sites. So while these homespun pages reflect the design skills of their authors, there also seems to be an effort by authors to avoid the glossy uniformity of the institutional pages and represent themselves in more authentic ways; constructing a persona independent of the idealised academic self of the university page.

Stripped of institutional branding and almost Spartan in their lack of extravagance and colour, this minimalism conveys a certain integrity to the individual. Here the absence of razzmatazz and a focus on content suggest someone removed from the promotional culture of modern academic life in which academics are simply the means to sell educational products. Although predominantly structured around professional content, the overall image is one which projects an identity for the subject which resonates with a very different view of scholarship, where academics are not simply commodities and students are clients but which conveys a passion for learning and a curiosity about some aspect of the world. Here, then, the academic reclaims some individuality and presents a more learned persona.

In addition to distinctive design features, authors also sought to signify a different self through a greater number and variety of photographs than on the university-hosted pages. The fact that personally-managed sites extended to several pages offered authors greater opportunities to represent themselves and their offline lives visually and they used this to post photographs of subjects other than themselves (Table 1).

Table 1: Photographs in university and personally managed academic homepages

\begin{tabular}{lcccc}
$\begin{array}{l}\text { Homepage } \\
\text { type }\end{array}$ & $\begin{array}{l}\text { total number } \\
\text { of photographs }\end{array}$ & $\begin{array}{l}\text { author } \\
\text { alone }\end{array}$ & $\begin{array}{l}\text { author with } \\
\text { others }\end{array}$ & $\begin{array}{l}\text { photographs } \\
\text { without author }\end{array}$ \\
University & 48 & 48 & 0 & 0 \\
Personal & 249 & 39 & 5 & 205 \\
\hline
\end{tabular}


In stark contrast to the formal passport-style portraits on university pages, photos of the author alone comprised just $15 \%$ of the total on the self-managed pages. Moreover, over half of these showed the subject engaged in some leisure activity and another five with family or friends, thus exhibiting social information about the self which is not recoverable from the university page, or indeed from the local text. Here we see a more rounded individual with hobbies, interests and relationships unconnected to those narrowly depicted on the university staff pages. $20 \%$ of the images were actually of people other than the homepage subject, most often children and family members, so revealing the writer as someone with a life beyond the confines of the university; an individual among academics. In addition to constructing this personal identity through photographs of people, pets figure fairly often, so that one academic, for example, included 18 pictures of his cats under the link 'my extended family' and another offered line drawings of his birds.

In this context, then, the visual does not just superficially embellish text, but can play a central semiotic role in presenting the self, allowing the individual to recover some of the subjectivities that are lost on the institutional page. But although many authors use this online space to make rich linkages to an off-line self, these pages are not entirely independent of the university to which they belong. $21 \%$ of all the photographs here were of the covers of journals that the page-owner edited or books they had written and another $26 \%$ included photographs of aspects of their trade, such as items of esoteric laboratory equipment, electron microscopic images and iconic figures of the field. Despite the considerable differences in the use of photographs between these self-constructed and university pages, authors did not lose sight of their academic identities and sought to associate themselves with their professional work, albeit often with greater zeal and commitment.

\subsection{Textual choices}

There was less of a contrast with the university homepages in the textual content of these personal pages. Table 2 shows that authors gave slightly less emphasis to the trappings of a scholarly identity on their personal pages, but there is broad similarity of topics with about $80 \%$ of them mentioning their employment and research. 
Table 2: Homepage authors mentioning various social characteristics (\% of all academics)

Employment Research Publications Education Teaching Awards Personal Service

$\begin{array}{lllllllll}\text { University pages } & 96 & 91 & 83 & 52 & 34 & 14 & 14 & 12 \\ \text { Personal pages } & 61 & 81 & 79 & 26 & 55 & 9 & 22 & 14\end{array}$

The discipline of the author appears to make little difference to what subjects have to say about themselves and, overall, few authors exploited the opportunity to offer a more multifaceted identity. Often accessed from a university sponsored page, the academic self is prominent in these pages with references to teaching, research and publications predominating. While some listed more personal qualities such as interests, hobbies, religion, likes and dislikes, etc., eight of the 50 pages were simply a curriculum vitae with no other information and just eighteen gave any personal information at all.

Only five authors mentioned their families, for example, although such mentions were often incorporated into their professional identities (links underlined):

(4) Back in the real world, I'm married to Jane and we have a young son, James. Here's my photo and here (from 1994) was my idea of fun.

Hewitt has included her family in her work. She is married to Robert Redwine, Ph.D.,

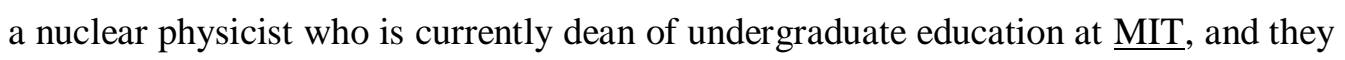
have 11- and 16-year-old sons. Together they have traveled the world to visit new observatories. She hopes that once the Mileura telescope is completed, she can convince her family to travel there with her

Reference to the author's family clearly puts flesh on the bones of the subject as a faceless academic churning out papers and teaching classes, here is a more human, more individual actor with a life beyond the lab or library and an identity that is more than screen deep.

Interestingly, and as in the university pages, men were more likely to reveal information about their personal lives. Like the adolescents in Chandler and Roberts-Young's (1998) study, they sought to reveal something of themselves through their wider interests, drawing selectively on objects and imagery from popular culture which 'provide a shared and easily available source of cultural options' 
(ibid: 8):

(5) I really enjoy music. My favorite genres tend to be progressive metal (e.g.

Mastodon, Isis) and progressive rock (e.g. Yes, King Crimson), but many of the artists I like do not fit into either of these categories (e.g. John Coltrane, Allan

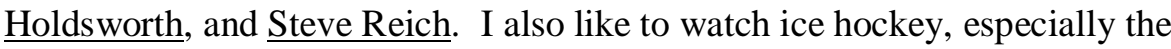

$\underline{\text { Pens }}$ and the Flyers. I have a great appreciation for the beers of the Chouffland.

It is unclear why males were more likely to reveal this kind of information, although Tannen (1990)

might suggest that it is related to males' predilection for collecting, listing and imparting facts.

More interesting that what authors' said, are the ways they said it. While largely choosing to represent an academic self to the world on their personal homepage, writers often found more idiosyncratic and distinctive ways of doing so. The personal page is a site where the institutional representation can be both extended and tempered by a more creative and expressive account of the self: a personal depiction of an individual rather than a corporate rendition of an employee. More than anything, therefore, it is the way that this content is conveyed which distinguishes the personal from the university homepage, as figure 3 illustrates.

Figure 3: 'Personal Page': a self-maintained academic homepage.

\section{Ian Howarth's Personal Page}

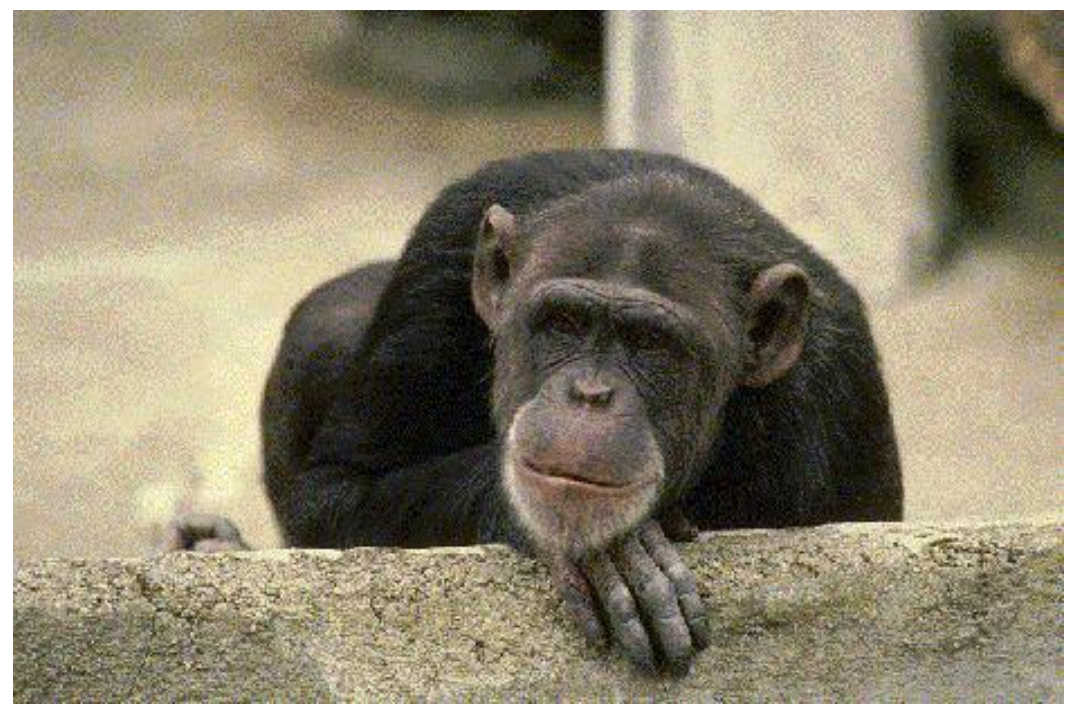

It's cool to be hot!

You should probably be looking elsewhere... 
I'm a Professor of Astronomy at UCL, and a member of the Massive Stars \& Clusters subgroup.

I was born -- very recently -- in Portsmouth (aka 'Sunny Southsea' in the brochures), and am thereby condemned to follow the very variable fortunes of its Football Team. I now live in Rickmansworth, Hertfordshire; the area's other famous residents include the glamorous and talented Cilla Black, and former England, Arsenal and Man City goalkeeper David Seaman.

My research interests span all the Hot-Star Group's projects, and I'm also interested in interstellar absorption-line spectroscopy and the applications of statistical techniques in astronomy. I was a 'back-yard' astronomer before starting my professional career, and still follow amateur activities, especially variable-star work, with interest. I've been Senior Secretary to, and Vice-President of, the Royal Astronomical Society, and maintain a mirror of the Astronomy Picture of the Day.

Outside the Department, I enjoy the complete suite of dweeb passtimes: listening to The Archers, birdwatching, politely refusing alcoholic beverages... Unfortunately, having been born too late for The Age of Steam, I never developed into train-spotting.

My favourite things include: hamsters, Rocky Mountain National Park, Here and There in The Observatory magazine.

Two clicks removed from a university-sponsored homepage, this page constructs a richer identity for the author. There is greater biographical detail here, with hobbies, personal likes and humour contributing to the creation of a different self to the university constructed academic on the institutionsponsored homepage. The photograph of the languid chimp, the tongue-in-cheek mention of the author's home-town celebrities, and the self-deprecating list of "dweeb pastimes", acknowledging a rather over-studious and perhaps socially inept individual, speaks to a more complex and rounded character than the university poster-boy. Despite this, however, he ensures that much of what is constructed here is his academic self and that key aspects of the homepage are related to his profession and discipline. The first link, for example, points the reader 'elsewhere' - to his professional homepage - and the following two links are to his research groups at his university. The longest paragraph plots his research interests and links to professional groups.

\subsection{Identity by association: links and connections}

Links on personal pages also contribute to a more distinctive identity than on university-managed pages by helping authors to create a network of more personally meaningful connections. The relationships expressed through these links allow authors to escape monologism by creating a pseudo- 
dialogue with the reader, individualizing their pages through associations of their own choosing to explicitly claim membership of particular groups, approval for particular ideas and relationships with particular others. Table 3 shows that while departmental and university links occurred in every academic's institutional page, authors chose to expand connections to their publication and research interests in their personal pages, showcasing themselves as academics rather than their institutions.

Table 3: Target pages of links on academic homepages

\begin{tabular}{|c|c|c|c|c|c|c|c|c|}
\hline & University & Dept. & Discipline & Students & Publication & Research & Personal & Totals \\
\hline \multicolumn{9}{|l|}{$\begin{array}{l}\text { University } \\
\text { pages }\end{array}$} \\
\hline Total links & 94 & 232 & 35 & 118 & 105 & 67 & 79 & 730 \\
\hline$\%$ of links & 12.9 & 31.8 & 4.8 & 16.0 & 14.2 & 9.2 & 11.1 & 100 \\
\hline Total authors & 50 & 50 & 16 & 41 & 21 & 38 & 50 & \\
\hline \multicolumn{9}{|l|}{$\begin{array}{l}\text { Personal } \\
\text { pages }\end{array}$} \\
\hline Total links & 52 & 43 & 80 & 85 & 393 & 63 & 88 & 804 \\
\hline$\%$ of links & 6.5 & 5.3 & 10.0 & 10.6 & 48.9 & 7.8 & 10.9 & 100 \\
\hline Total authors & 22 & 25 & 26 & 29 & 41 & 33 & 29 & \\
\hline
\end{tabular}

Disciplinary links are also far more important in these pages, taking readers to affiliated labs, journal websites, professional associations, and so on, and most academics further personalised their pages by providing links to their publications, connecting to bibliographies, online bookstores and pdfs.

Physicists in particular included links to their research interests or, more often, to their research group, with five times more links than philosophers. These examples from personal pages are typical (links underlined):

(1) I am a member of the STAR and ALICE collaborations. Click on the images to see what I work on:

\begin{tabular}{ll}
$\underline{\text { STAR }}$ & $\underline{\text { STAR Strangeness Group }}$ \\
\hline ALICE
\end{tabular}

Our group is a member of the Compact Muon Solenoid (CMS) experiment, which has constructed a massive detector for the Large Hadron Collider (LHC). The LHC is a $14 \mathrm{TeV}$ proton-proton colliding beam accelerator, which has been constructed at the European accelerator center, CERN, in Geneva, Switzerland. To find out more, visit the CMS web page and CERN's web page. 
Here writers seem to take the opportunity not only to represent themselves as academics through the labs and groups they are associated with, but to promote those to wider scholarly communities.

Links on personal pages not only have the advantage of promoting the individual's academic credentials in a way determined by the author rather than the institution, but can also call the reader to selected aspects of the self which are not available to them on university pages. Few academics exercised this option, however, so while the appearance of the pages differed from the university pages, the content and the links tended to mirror the university sites. While some individuals sought to present something different about themselves, with links to the Star Trek website or the chorus from a Verdi opera, they essentially presented an academic biography, as in this example (links underlined):

(8) Past President of the Australasian Association of Philosophy, Member of the editorial boards of The Bulletin of Symbolic Logic, and The Australasian Journal of Philosophy, Fellow of the Australian Academy of the Humanities, Chief Investigator in the Australian Centre of Excellence for Risk Analysis, Core Researcher in the Commonwealth Environment Research Facilities Research Hub: Applied Environmental Decision Analysis, Member of the Biotechnology, Ethics, Law and Society Network.

This emphasis is even apparent in cases where authors have individualized their sites with a more human face. One author, uniquely in this corpus, presented his page in the form of a blog, seeking a more interactive and personal mode of engagement, but the links, and content, are professional:

(9) I've been writing. Doing lots of writing. You'll see a few changes on the writing page. I'm most happy with the new paper "A Cut-Free Sequent System for Two-Dimensional Modal Logic: and why it matters." There's a little philosophy there, and a little proof theory, too. I'd appreciate your comments. Head over to the paper page to download the paper and post your comments. My next travels involve a trip to Guangzhou to take part in SELLC 2010. That's going to be a blast, helping teach a Winter School to a bunch of enthusiastic students, and with a great slate of lecturers. It'll be good to catch up with my colleagues at the ILC at Sun Yat-Sen University. On the way home from Guangzhou, I'll take a quick side trip to Boston for the Eastern APA, to contribute to a session on the future of logic, with John Horty and Johan van Benthem. 
The interpersonal tone of this extract helps shift the boundaries between the professional and personal, yet remains firmly and predominantly constitutive of an academic identity. This is an individual comfortable using contemporary communications media and who maintains a twitter feed and a blog, but at the same time, it is someone whose publicly projected face is an academic one.

\section{Discussion}

The representation of the academic which the university homepage makes available is constructed entirely on the institution's terms, requiring the subject to conform to its norms and implicitly subscribe to its corporate ideologies. The design and emblematic choices of these pages function to merge the individual with the institution and are generally devoid of individuality. Negotiating a representation of self from these standardizing conventions is clearly a difficult task, so the decision to create a personal homepage might be seen as an opportunity to shape a richer and less onedimensional identity. In fact, we find that academics are able to display greater individuality and distinctiveness within the personally managed spaces they construct for themselves. Through photographs of friends, pets and family members; through links to personal icons, hobbies, and interests; and through D-I-Y design features, many of these academics seek to reclaim aspects of their identity disregarded within a uniform institutional representation.

Despite a certain idiosyncratic design and a greater focus on the individual, however, it is the academic self which greets visitors to these sites. Most subjects chose to limit their selfrepresentation to an academic profile: deliberately withholding pieces of social information which would allow them to reveal a fuller identity. It may be asked what is lost by this? Why do academics need to present themselves as anything other than academics on these pages? They don't, of course, have to say anything more about themselves than they do now, but too often what is missing in many of these pages is any sense of authors' creative self-expression or individuality. We can see from the more ingeniously designed pages I have quoted that inventiveness is possible and that avoiding personal aspects of self does not simply follow from being a professional. 
Clearly there are issues of privacy and disclosure here which may figure in individual decisions, but presumably one purpose of a homepage is precisely the opportunity it provides for disclosure and selfpresentation. By creating a homepage subjects are actually making a decision to make information about themselves public, thus blurring issues of privacy and security, but they are also choosing to participate in a medium where there are strong expectations of personal disclosure. Other electronic media such as Facebook, Myspace, and Twitter, for example, have grown popular precisely because they allow users to broadcast very private information (such as location, relationship status, etc.). New search engines take intrusion even further, so that Spokeo compiles profiles of individuals by collecting and aggregating data such as age, marital status, estimated personal wealth, family and home address. In this context of online visibility, then, the decision to present only a professional face to the world generates implicatures about the individual: in a medium of personal disclosure, minimal disclosure suggests that the bland academic presented is all there is.

More probing with individual authors is needed to explain why many writers choose to project an identity which, while stepping beyond that of the bland functionary depicted by their universities, remains firmly linked to it. It is possible that they believe there are career risks involved in providing information about themselves which may distract readers from their adherence to their employing institutions. Many of these personal sites are located on university servers and so symobilze 'the allusion of institutional governmentality, from which norms are perceived and adhered to in order to remain a moral citizen of that (virtual) community' (Thoms \& Thelwall, 2005). Representing themselves in an unexpected fashion might then be seen as challenging the coercive power of their university - with potential career consequences.

On the other hand, it may be that they see their academic selves as central to their identity, at least in this context. Omitting whatever else fills their lives and contributes to their self-esteem and selfconceptions is not, then, relinquishing ownership of their identities to their employers but simply irrelevant to how they want to be seen. Here the personal homepage is an opportunity for authors to increase their visibility to their wider disciplinary and scholarly community by filling-in the academic 
gaps left by the bare-bones outline of themselves on the university page. It offers a vehicle to move from their university-managed profile to a disciplinary one. The personal homepage is therefore a site to reinforce credentials and to underline a right to be seen as a member of an academic community.

It seems, however, crucial for authors to remember that in constructing a professional identity they are also constructing a personal one, revealing themselves as a particular kind of person with particular goals, preferences and behaviours. The resources the homepage genre offers for representing ourselves, our allegiances, our experiences and our ideas are not simply the raw materials of constraint. But because the performance of identity on a personal homepage lacks the social and paralinguistic cues of face-to-face interaction, readers access to information about the author is through what is said and through the links and design features associated with what is said. In other words, all they have to go on is what they can see, and if all they see is a professional academic, then there may be little to distinguish that person from the countless other academics that inhabit the web.

\section{Conclusions}

Both membership of a community and separateness from that community, or assimilation to the group and differentiation from it, are central to identity. Identity helps characterize both what makes us similar to and different from each other. For academics, it is how they simultaneously achieve credibility as insiders and reputations as individuals. This means that a representation that leans too far towards similarity can slide into conformism just as an overemphasis on individuality can easily undermine one's membership of a disciplinary community. Thus while there may be some, perhaps implicit, pressures on academics to conform to particular conventions and to represent themselves in certain ways online, there are costs to limiting self-representations to those of a journeyman academic and honest employee. An impressive publications list or collection of prizes may be one way to carve an individual persona, demonstrating a virtuosity in one's field, but as Ian Howarth's page suggests, another is to reveal a human face behind the monographs and articles. 
Clearly the issues surrounding personal and community identity are complex and, in the end, the dichotomy in the title of this paper is a false one. Like other areas of social activity, academic life involves both individuality and conformity: complying with institutional conventions and norms and distinguishing oneself from the herd. In this paper I have attempted to show that what individuals chose to say about themselves, and how they choose to say it, indexes identity, but I have also tried to raise questions about what kind of identity this is. The homepage is a site where similarity and difference, conformity and idiosyncrasy are played out, and its further study can reveal more about identity as the performance of an independent creativity accountable to institutional practices.

\section{References}

Arnold, Jill \& Miller, Hugh. (2001). Breaking away from grounded identity? Cyberculture and gendered academic identities on the web. Paper presented at Constructing cyberculture(s): Performance, pedagogy and politics in online spaces, College Park, MD.

Becher, Tony and Trowler, Paul. (2001). Academic Tribes and Territories: Intellectual Inquiry and the Cultures of Disciplines. Milton Keynes: SRHE and Open University Press.

Bonnardel, Nathalie, Piolat, Annie \& Le Bigot, Ludovic. (2010). The impact of colour on website appeal and users' cognitive processes, Displays doi: 10.1016/j.displa.2010.12.002

Chandler, David. (1998). Personal homepages and the construction of identities on the web. Paper presented at Aberystwyth Post-International Group Conference on Linking theory and practice: issues in the politics of identity, 9-11 Sept. 1998. University of Wales.

http://www.aber.ac.uk/media/Documents/short/webident.html

Chandler, David \& Roberts-Young, Dilwyn. (1998). The construction of identity in the personal homepages of adolescents. http://www.aber.ac.uk/media/Documents/short/strasbourg.html

Danath, Judith \& Boyd, Danah. (2004). Public displays of connection. BT Technology Journal, 22 (4) $1-11$.

Dumont, Kitty \& Frindte, Wolfgang. (2005). Content analysis of the homepages of academic psychologists. Computers in Human Behavior 21, 1: 73-83 
Fairclough, Norman. (1995). Critical Discourse Analysis. Harlow: Longman.

Gergen, Kenneth. (1991). The saturated self: dilemmas of identity in contemporary life. New York: Basic Books.

Giddens, Anthony. (1991). Modernity and self-identity.: self and society in the late modern age. Cambridge: Polity Press.

Hawisher, Gail \& Sullivan, Patricia. (1999). Fleeting images: women visually writing the web. In Hawisher, G. \& Sullivan, P. (eds.) Passions, pedagogies and $21^{\text {st }}$ century technologies (pp 168291). Logan, UT: Utah State University Press.

Hess, Micky. (2002). A nomad faculty: English professors negotiate self-representation in university web space. Computers and composition. 19 (2): 171-189.

Hyland, Ken (2012). Disciplinary identities. Cambridge University Press.

Jaffe, J. Michael, Lee Young-Eum, Huang, LiNing \& Oshagan, Hayg. (1995). Gender, Pseudonyms and CMC: Masking Identities and Baring Souls. Paper presented at the 45th Annual Conference of the International Communication Association, Albuquerque, New Mexico. http://research.haifa.ac.il/ jmjaffe/genderpseudocmc/

Kraus, Wolfgang. (2000). Making identity talk. On qualitative methods in a longitudinal study. FQS 1, 2. http://www.qualitative-research.net/index.php/fqs/article/view/1084

Kress, Gunther. \& van Leuwen, Leo. (1996). Reading images: the grammar of visual design. London: Routledge.

Levi-Strauss, Claude. (1974). The savage mind. London: Weidenfeld \& Nicolson.

Parks, Malcolm R. \& Archley-Landas, Tony. (2003). Communicating self through personal homepages: is identity more than screen deep? Paper presented at the Annual Conference of the International Communication Association, San Diego, CA.

QS-Times Higher world University rankings for 2010 (2011). Retrieved July 2011 from http://www.topuniversities.com/university-rankings/world-university-rankings/2010

Rheingold, Harold. (1995). The virtual community: finding connection in a computerized world. London: Minerva.

Tannen Deborah. (1990). You just don't understand: women and men in conversation. New York: 
Ballantine,

Thoms, Lesley \& Thelwall, Mike. (2005) . Academic home pages: reconstruction of the self.

First Monday . 10(12), http://www.firstmonday.org/issues/issue10_12/thoms/

Turkle, Sherry. (1996): Life on the screen: identity in the age of the internet. London: Weidenfeld \& Nicolson

Wynn, Eleanor, \& Katz, James E. (1997). Hyperbole over cyberspace: Self-presentation and social boundaries in internet home pages and discourse. The Information Society, 13(4), 297-328. 